\title{
Beforehand transection and suturing (BTS) of the dorsal vascular complex: a novel technique in laparoscopic radical prostatectomy
}

\author{
Jun-Wei Pan ${ }^{1 \#}$, Xing-Wei Jin ${ }^{1 \#}$, Fang-Xiu Luo ${ }^{2}$, Wei Jin ${ }^{3}$, Wei-Chao Tu ${ }^{1}$, Xiang Zhang ${ }^{1}$, Xian-Jin Wang ${ }^{1}$, \\ Bao-Xing Huang ${ }^{1}$, Da Xu ${ }^{1}$, Guo-Liang Lu ${ }^{1}$, Yang Zhao ${ }^{1}$, Yuan Shao ${ }^{1}$ \\ ${ }^{1}$ Department of Urology, Ruijin Hospital, Shanghai Jiao Tong University School of Medicine, Shanghai, China; ${ }^{2}$ Department of Pathology, Ruijin \\ Hospital, Shanghai Jiao Tong University School of Medicine, Shanghai, China; ${ }^{3}$ Department of Anesthesiology, Ruijin Hospital, Shanghai Jiao Tong \\ University School of Medicine, Shanghai, China \\ Contributions: (I) Conception and design: JW Pan; (II) Administrative support: Y Shao; (III) Provision of study materials or patients: JW Pan, XW Jin, \\ FX Luo, W Jin, WC Tu, X Zhang, XJ Wang, BX Huang, GL Lu, Y Zhao; (IV) Collection and assembly of data: JW Pan, XW Jin; (V) Data analysis \\ and interpretation: JW Pan, XW Jin; (VI) Manuscript writing: All authors; (VII) Final approval of manuscript: All authors. \\ \#These authors contributed equally to this work. \\ Correspondence to: Yuan Shao. Department of Urology, Ruijin Hospital, School of Medicine, Shanghai Jiao Tong University, 999 Xi Wang Road, \\ Shanghai 201801, China. Email: shaoyuan15@hotmail.com.
}

\begin{abstract}
Backgroundk Beforehand transection and suturing (BTS) of the dorsal vascular complex (DVC), a novel technique in non-neurovascular bundle sparing (NVB-sparing) extraperitoneal laparoscopic radical prostatectomy (eLRP), had been proposed; this study aimed to evaluate this technique in clinical laparoscopic procedures.
\end{abstract}

Methods: Using this new technique, the DVC was transected and sutured after dissection of the pelvic fascia and before dissection of the prostate, especially before ligation of the bilateral prostatic pedicles. This study retrospectively analyzed the data of 90 non NVB-sparing eLRP patients [traditional technique $(\mathrm{n}=60)$ and BTS technique $(\mathrm{n}=30)]$.

Results: The surgical time in the BTS technique group was $121.73 \pm 24.53 \mathrm{~min}$, which was significantly shorter $(\mathrm{P}=0.0015)$ than the traditional technique group $(144.12 \pm 39.68 \mathrm{~min})$. The calculated blood loss in the traditional technique group was $388.45 \pm 232.78 \mathrm{~mL}$, and $264.16 \pm 130.70 \mathrm{~mL}$ in the BTS technique group $(\mathrm{P}=0.0016)$. The estimated blood loss in the traditional technique group was $350.34 \pm 311.80 \mathrm{~mL}$, which was significantly greater than the BTS technique group $(250.33 \pm 145.31 \mathrm{~mL}, \mathrm{P}=0.0422)$. The transfusion rate in the traditional technique group was significantly greater than the BTS technique group (15.00\% vs. $0.00 \%$; $\mathrm{P}=0.0266)$. The biochemical recurrence rate in traditional technique group was $48.33 \%$, which was higher than in the BTS group (30.00\%) ( $\mathrm{P}=0.0465)$. There was no significant difference between the 2 groups with respect to the pre-operative hemoglobin $(\mathrm{Hb})$ concentration, pre-operative hematocrit (HCT), postoperative $\mathrm{Hb}$ concentration, post-operative HCT, $\triangle \mathrm{HCT}$, pre-operative blood volume, rectal perforation, open conversion, apical capsule residue, false suture, post-operative bleeding, urinary leakage, re-operation, surgical site infection, post-operative stay, and emission time of urinary incontinence.

Conclusions: In managing the relationship between the DVC and prostate in patients undergoing non NVB-sparing eLRP, the BTS technique was shown to be more effective and safer than the traditional technique.

Keywords: Beforehand transection and suturing technique (BTS technique); dorsal vascular complex (DVC); extraperitoneal laparoscopic radical prostatectomy (eLRP); prostatic pedicles

Submitted Oct 12, 2020. Accepted for publication Dec 16, 2020.

doi: $10.21037 /$ gs-20-813

View this article at: http://dx.doi.org/10.21037/gs-20-813 


\section{Introduction}

The laparoscopic prostatectomy provides a more favorable and clear view which leads to a deeper understanding of the anatomy of prostate and further a anatomical dissection of prostate during the surgery. When using the traditional technique for managing the dorsal vascular complex (DVC) during non-neurovascular bundle sparing (NVB-sparing) extraperitoneal laparoscopic radical prostatectomy (eLRP), the DVC is ligated after incision of the bilateral endopelvic fascia [whitish line (1)], but is not transected. It is not until the apex has been separated, that the DVC division is further processed. This surgical sequence might be designed in considering of the bleeding of DVC and prostatic lateral ligaments. So it is not until that both of the DVC and the bilateral prostatic lateral ligaments are controlled, will the DVC be transected. There are several shortcomings of the traditional technique, as follows: (I) difficulty identifying the DVC-urethra plane; (II) challenging technology of DVC dissection and suturing; (III) false suturing of the urethra or catheter; (IV) incomplete suturing of DVC; (V) augmentation of bleeding (2) due to the difficulty of suturing; (VI) difficulty of suturing a short or broad DVC (3), which is due to pelvic adhesions or excessive fusion of parietal and visceral components of the endopelvic fascia (1); (VII) difficultly dissecting the prostate when the prostate to true pelvic volume ratio is high (3); (VIII) difficulty suturing the DVC and dissection of the prostate in cases of prominent pubic tubercles (3); and (IX) loosening, displacement, or breakage of the sutures resulting in further bleeding (2), and difficulty in separating the apex and the apex residue (4).

A novel technique, beforehand transection and suturing (BTS), through which the sequence of eLRP surgery was improved, was proposed by the surgeon, Jun-wei Pan. The DVC was transected and sutured (2-0 V-Loc $\left.{ }^{\mathrm{TM}}\right)$ before antegrade separation of the prostate utilizing the BTS technique, which aimed to avoid the above-mentioned shortcomings to the maximum extent. This study was to compare the BTS technique and the traditional technique in eLRP and to evaluate the value of the novel technique.

We present the following article in accordance with the STROBE reporting checklist (available at http://dx.doi. org/10.21037/gs-20-813).

\section{Methods}

\section{BTS technique}

The pre-prostate fat was dissected during an eLRP and sent for pathologic evaluation. After excision of the pre-prostatic fat (5) and incision of the pelvic fascia, the pubovesical ligament and DVC were exposed. The preference, but not requirement, was to continue the dissection as close as possible to the DVC-urethral space or the point that the DVC, urethra, and prostate connect. We placed 2 stitches are superficially using 2-0 V-Loc ${ }^{\mathrm{TM}}$ (Covidien, Mansfield, MA, USA) or 1 stitch for the other non-barbed suture (Figure 1). In this step, the suture of the entire DVC was not essential. Pneumoperitoneal pressure was increased to $18 \mathrm{mmHg}$ (4). Before antegrade separation of the prostate, the DVC was immediately transected using an ultrasound knife until the anterior wall of urethra was exposed (Figures 2,3), then the distal DVC stump was stitched in a proximal-distal-proximal fashion (Figure 4). A smallsized Hem-o-Lok ${ }^{\mathrm{TM}}$ (Ethicon Endo-surgery, Johnson \& Johnson, Cincinnati, OH, USA) was utilized to consolidate the suture or as tying for the other non-barbed suture (Figure 5). In cases involving active bleeding caused by 2 arterioles in the DVC, alternate transection and stitching was performed. Suction or aerofluxus via the trocar was considered hazardous in this transecting and suturing procedure. After satisfactory suturing of the DVC was assured, antegrade separation of the prostate was continued with a pneumoperitoneal pressure of $15 \mathrm{mmHg}$. There was no need to further control the proximal stump of the DVC with a stitch or Hem-o-Lok ${ }^{\mathrm{TM}}$. Occasionally, bipolar forceps were utilized to coagulate the small retrograde blood flow. Thus, the DVC was treated beforehand, especially before ligation of the bilateral prostatic pedicles.

\section{Participant selection}

A total of 90 patients who underwent a non NVB-sparing eLRP to cure prostate cancer in the Department of Urology at Shanghai Ruijin Hospital North from January 2018 to December 2019 were selected for this study. The traditional technique was performed in 60 patients, while the BTS technique was performed in 30 patients.

\section{The eLRP and traditional techniques}

An ordinary four-port extraperitoneal approach, Trendelenburg position, and pneumoperitoneal pressure of $15 \mathrm{mmHg}$ were applied during all surgeries. The operative procedure in the traditional technique group was advanced in order, as follows: separation of pre-prostatic fat; incision of endopelvic fascia; suture and ligation of 


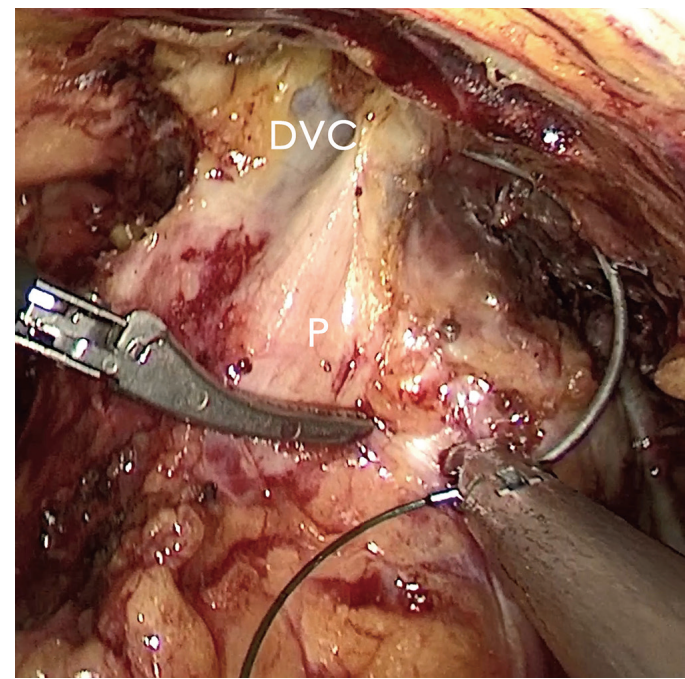

Figure 1 Two stitches were made superficially using 2-0 V-Loc. DVC, dorsal vascular complex; $\mathrm{P}$, prostate.

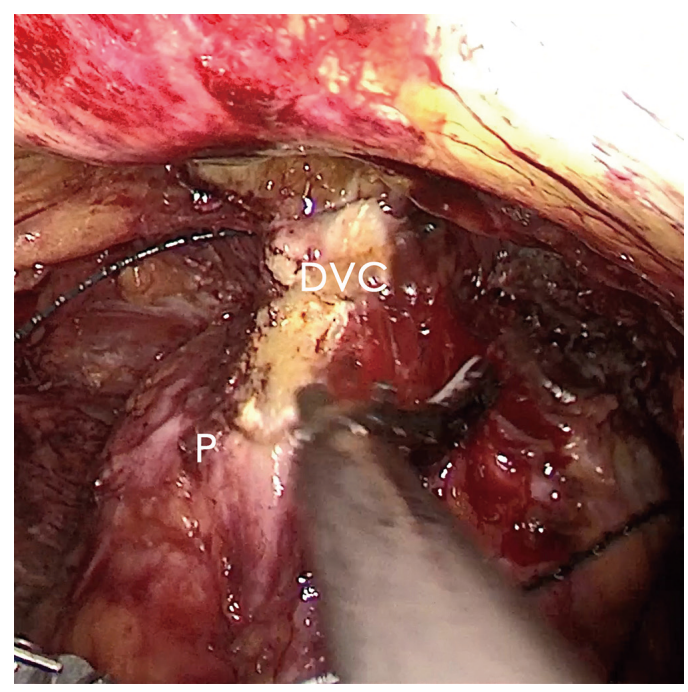

Figure 2 Before antegrade separation of the prostate, the DVC was immediately transected by an ultrasound knife until the anterior wall of the urethra was exposed. DVC, dorsal vascular complex; P, prostate.

the DVC; transection of the vesicoprostatic junction; transection of the deferent ducts; dissection of the seminal vesicles; separation of Denonvilliers' fascia; transection of the lateral prostatic ligaments; transection of the DVC; dissection of the apex; transection of the urethra; digital rectal examination; anastomosis of the urethra and bladder neck with or without reconstruction of the bladder neck;

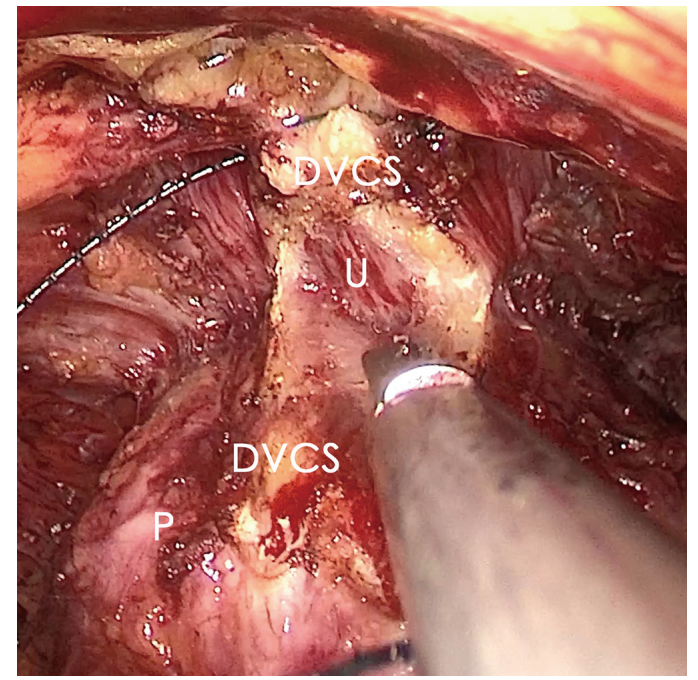

Figure 3 The anterior wall of the urethra was exposed. DVCS, dorsal vascular complex stump; $\mathrm{P}$, prostate; $\mathrm{U}$, urethra.

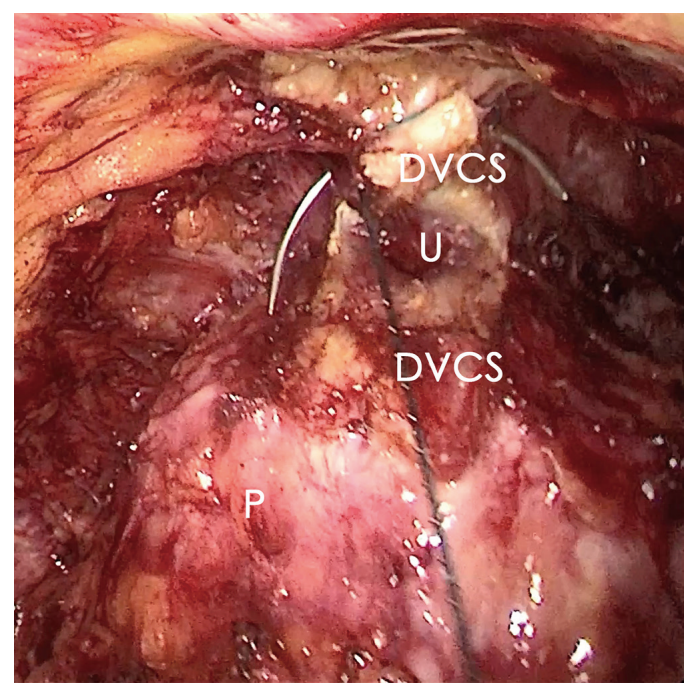

Figure 4 The distal DVC stump was stitched in a proximaldistal-proximal fashion. DVCS, dorsal vascular complex stump; $\mathrm{P}$, prostate; U, urethra.

placement of a 22 Fr tri-cavity catheter and pelvic drainage; and incision closure.

\section{Parameters}

General data, including age, body mass index (BMI), preoperative prostate-specific antigen (PSA) level, prostate 
volume, number of positive punctures, grade groups according to the 2014 International Society of Urological Pathology grading system (6), and neoadjuvant therapy rate were gathered in the traditional and BTS technique groups. These data were subsequently analyzed.

The post-operative paraffin pathology data from the 2 groups were also collected and analyzed with respect to pathologic sort, capsule invasion rate, seminal vesicle invasion rate, deferent duct margin-positive rate, nerve invasion rate, vessel tumor thrombus-positive rate, bladder neck invasion rate, pre-prostatic lymph node metastasis rate, obturator lymph node metastasis rate, other lymph node metastasis rate, and proportion of $\mathrm{pT} 2 \mathrm{a}-2 \mathrm{~b}, \mathrm{pT} 2 \mathrm{c}$, pT3a, pT3b, and pT4a.

The following peri-operative parameters were recorded and compared between the 2 groups: surgery time (ST); pre-

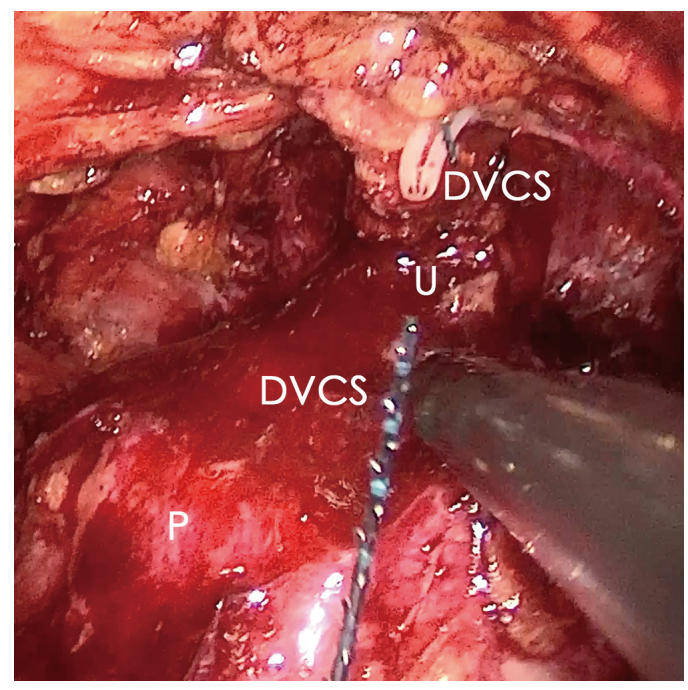

Figure 5 A small-sized Hem-o-Lok was utilized to consolidate the suture. DVCS, dorsal vascular complex stump; P, prostate; U, urethra. operative hemoglobin $(\mathrm{Hb})$ concentration; pre-operative hematocrit (HCT); post-operative $\mathrm{Hb}$ concentration; postoperative HCT; $\triangle \mathrm{HCT}$; pre-operative blood volume (PBV); calculated blood loss $\left(\mathrm{BL}_{\mathrm{c}}\right)$; estimated blood loss $\left(\mathrm{BL}_{\mathrm{e}}\right)$; transfusion rate; rectal perforation rate; open conversion; false suture; apical capsule residue; post-operative bleeding rate; urinary leakage rate; re-operation rate; operative area infection rate; and post-operative stay, remission time of urinary incontinence and biochemical recurrence rate. The post-operative $\mathrm{Hb}$ concentration, and post-operative HCT were measured on the first post-operative day. The blood loss could not be precisely calculated from the liquid collected in the suction container mixed with urine; therefore, the $\mathrm{BL}_{\mathrm{e}}$ recorded was commonly estimated by the anesthesiologists and surgeons. The prostate volume, $\triangle \mathrm{HCT}$, and $\mathrm{BL}_{\mathrm{c}}$, were calculated according to the equation or formula below $(7,8)$ (Table 1$)$.

\section{Statistical analysis}

The data were analyzed using SAS version 8 (SAS Institute Inc., North Tustin, CA, USA). The data are presented as the mean \pm standard error of the mean (SEM). The homogeneity test of variance, group $t$-test, chi-square test $\left(\chi^{2}\right)$ of a four-fold table, Fischer exact test, and Wilcoxon two-sample test were used to analyze the differences between the 2 groups. Differences were considered significant at a $\mathrm{P}$ value of $<0.05$.

\section{Statement of Institutional Review Board (IRB) Approval}

All procedures performed in this study involving human participants were in accordance with the Declaration of Helsinki (as revised in 2013). The study was approved by institutional ethics committee of Shanghai Ruijin Hospital and informed consent was taken from all the patients.

Table 1 Formula of reference

\begin{tabular}{lll}
\hline Formula & & Description \\
\hline Ellipsoid & Prostate volume $=$ Height $\times$ Width $\times$ Length & The 3 diameters on the longitudinal, axial, and transverse planes of prostate \\
Formula $(7)$ & $\times(\pi / 6)$ & were measured through magnetic resonance imaging $(\mathrm{MRI}) \Pi / 6=0.52$ \\
Gross & $\mathrm{PBV}=\mathrm{k}_{1} \times \mathrm{H}^{3}+\mathrm{k}_{2} \times \mathrm{W}+\mathrm{k}_{3}$ & $\mathrm{PBV}(\mathrm{mL}):$ preoperative blood volume \\
Formula (8) & $\mathrm{BL}=\mathrm{PBV} \times \Delta \mathrm{HCT} /(\Sigma \mathrm{HCT} / 2)$ & $\mathrm{H}(\mathrm{m}):$ height \\
& $\Delta \mathrm{HCT}=$ Preop HCT - Postop HCT & $\mathrm{W}(\mathrm{kg}):$ weight \\
& $\Sigma \mathrm{HCT}=$ Preop HCT + Postop HCT & For male, $\mathrm{k}_{1=} 0.3669, \mathrm{k}_{2=} 0.03219, \mathrm{k}_{3=} 0.6041$. \\
& & $\mathrm{BL}_{\mathrm{c}}:$ blood loss calculated \\
\hline
\end{tabular}


Table 2 General data statistics for the traditional and BTS technique groups

\begin{tabular}{|c|c|c|c|}
\hline General parameters & Traditional technique group $(n=60)$ & BTS technique group $(n=30)$ & $P$ value \\
\hline $\mathrm{BMI}\left(\mathrm{kg} / \mathrm{m}^{2}\right)$ & $23.64 \pm 2.86$ & $24.22 \pm 2.88$ & 0.3669 \\
\hline Preoperative PSA (ng/mL) & $21.80 \pm 25.33$ & $19.80 \pm 38.45$ & 0.7973 \\
\hline Prostate volume (mL) & $47.96 \pm 20.90$ & $42.13 \pm 18.10$ & 0.1939 \\
\hline Neoadjuvant therapy rate (n, \%) & $5(8.33)$ & $2(6.67)$ & 1.0000 \\
\hline
\end{tabular}

BTS, beforehand transection and suturing; BMI, body mass index; PSA, prostate-specific antigen.

Table 3 Pathology in the traditional and BTS technique groups

\begin{tabular}{|c|c|c|c|}
\hline Pathologic parameters & Traditional technique group $(n=60)$ & BTS technique group $(n=30)$ & $P$ value \\
\hline Acinar adenocarcinoma & $60(100.00)$ & $30(100.00)$ & - \\
\hline Capsule invasion (n, \%) & $16(26.67)$ & $4(13.33)$ & 0.1861 \\
\hline Seminal vesicle invasion $(n, \%)$ & $10(16.67)$ & $2(6.67)$ & 0.3239 \\
\hline Deferent duct margin positive (n, \%) & $5(8.33)$ & $1(3.33)$ & 0.6593 \\
\hline Nerve invasion (n, \%) & $29(48.33)$ & $10(33.33)$ & 0.0016 \\
\hline Bladder neck invasion (n, \%) & $0(0.00)$ & $2(6.67)$ & 0.1086 \\
\hline Pre-prostatic lymph nodes metastasis (n, \%) & $2(3.33)$ & $0(0.00)$ & 0.5506 \\
\hline pT2a-2b (n, \%) & $7(11.67)$ & $8(26.67)$ & 0.1308 \\
\hline pT2c (n, \%) & $32(53.33)$ & $16(53.33)$ & 1.0000 \\
\hline pT4a (n, \%) & $0(0.00)$ & $1(3.33)$ & 0.3333 \\
\hline
\end{tabular}

BTS, beforehand transection and suturing.

\section{Results}

\section{General data statistics}

All patients were followed up completely. No significant difference existed between the traditional $(\mathrm{n}=60)$ and BTS technique ( $\mathrm{n}=30$ ) groups (Table 2).

\section{Post-operative paraffin patbology}

The post-operative paraffin pathology of all patients was acinar adenocarcinoma. The capsule invasion rate in the traditional and BTS technique groups was $26.67 \%$ and $13.33 \%$ $(\mathrm{P}=0.1861)$, the seminal vesicle invasion rate was $16.67 \%$ and $6.67 \%(\mathrm{P}=0.3239)$, the deferent duct margin-positive rate was
$8.33 \%$ and $3.33 \%(\mathrm{P}=0.6593)$, the nerve invasion rate was $48.33 \%$ and $33.33 \%(\mathrm{P}=0.0016)$, the vessel tumor thrombuspositive rate was $5.00 \%$ and $3.33 \%(\mathrm{P}=1.0000)$, the bladder neck invasion rate was $0.00 \%$ and $6.67 \%(\mathrm{P}=0.1086)$, and the pre-prostatic lymph nodes metastasis rate was $3.33 \%$ and $0.00 \%$, respectively $(\mathrm{P}=0.5506)$. The grade pathologic T2a-2b (pT2a-2b) rate in the traditional and BTS technique groups was $11.67 \%$ and $26.67 \%(\mathrm{P}=0.1308)$, the grade $\mathrm{pT} 2 \mathrm{c}$ rate was $53.33 \%$ and $53.33 \%(\mathrm{P}=1.0000)$, the grade $\mathrm{pT} 3$ a rate was $18.33 \%$ and $6.67 \%(\mathrm{P}=0.2058)$, the grade $\mathrm{pT} 3 \mathrm{~b}$ rate was $16.67 \%$ and $10.00 \%(\mathrm{P}=0.5316)$, and the grade $\mathrm{pT} 4 \mathrm{a}$ rate was $0.00 \%$ and $3.33 \%$, respectively $(\mathrm{P}=0.3333)$. No patients were diagnosed with grade $\mathrm{pT} 4 \mathrm{~b}$. There was a significant difference in the nerve invasion rate (Table 3). 
Table 4 Comparison between the traditional and the BTS technique groups

\begin{tabular}{|c|c|c|c|}
\hline Operation-related parameters & Traditional technique group $(n=60)$ & BTS technique group $(n=30)$ & $P$ value \\
\hline Pre op Hb (g/L) & $130.92 \pm 14.74$ & $126.70 \pm 17.61$ & 0.2465 \\
\hline Pre op HCT (\%) & $37.73 \pm 4.16$ & $36.00 \pm 5.04$ & 0.0877 \\
\hline Post op Hb (g/L) & $103.32 \pm 12.55$ & $100.46 \pm 12.16$ & 0.3165 \\
\hline$\triangle \mathrm{HCT}(\%)$ & $8.47 \pm 3.43$ & $7.05 \pm 2.98$ & 0.0675 \\
\hline PBV (L) & $4.51 \pm 0.39$ & $4.48 \pm 0.46$ & 0.7419 \\
\hline $\mathrm{BL}_{\mathrm{c}}(\mathrm{mL})$ & $388.45 \pm 232.78$ & $264.16 \pm 130.70$ & 0.0016 \\
\hline $\mathrm{BL}_{\mathrm{e}}(\mathrm{mL})$ & $350.34 \pm 311.80$ & $250.33 \pm 145.31$ & 0.0422 \\
\hline Open conversion $(\mathrm{n}, \%)$ & $0(0.00)$ & $0(0.00)$ & - \\
\hline False suture (n, \%) & $1(1.67)$ & $0(0.00)$ & 1.0000 \\
\hline Apical capsule residue (n, \%) & $7(11.67)$ & $2(6.67)$ & 0.2379 \\
\hline Post op bleeding & $0(0.00)$ & $1(3.33)$ & 0.3333 \\
\hline Trocar incision bleeding (n, \%) & $0(0.00)$ & $1(3.33)$ & 0.3333 \\
\hline Urinary leakage $(n, \%)$ & $1(1.67)$ & $0(0.00)$ & 1.0000 \\
\hline Reoperation (n, \%) & $0(0.00)$ & $0(0.00)$ & - \\
\hline Operative area infection (n, \%) & $0(0.00)$ & $0(0.00)$ & - \\
\hline
\end{tabular}

BTS, beforehand transection and suturing; ST, surgery time; PBV, pre-operative blood volume; $\mathrm{HCT}$, hematocrit; $\mathrm{BL}_{c}$, calculated blood loss; $\mathrm{BL}_{\mathrm{e}}$, estimated blood loss.

\section{Peri-operative and postoperative comparison}

The ST in the BTS technique group was $121.73 \pm 24.53 \mathrm{~min}$, which was significantly shorter $(\mathrm{P}=0.0015)$ than the traditional technique group $(144.12 \pm 39.68 \mathrm{~min})$. There was no significant difference between the 2 groups with respect to the preoperative $\mathrm{Hb}$ concentration, pre-operative HCT, postoperative $\mathrm{Hb}$ concentration, post-operative HCT, $\triangle \mathrm{HCT}$, and PBV $(\mathrm{P}=0.2465,0.0877,0.3165,0.2654,0.0675$, and 0.7419 , respectively). The $\mathrm{BL}_{\mathrm{c}}$ in the traditional technique group was $388.45 \pm 232.78 \mathrm{~mL}$, and $264.16 \pm 130.70 \mathrm{~mL}$ in the BTS technique group $(\mathrm{P}=0.0016)$. The $\mathrm{BL}_{\mathrm{e}}$ in the traditional technique group was $350.34 \pm 311.80 \mathrm{~mL}$, and
$250.33 \pm 145.31 \mathrm{~mL}$ in the BTS technique group $(\mathrm{P}=0.0422)$. The transfusion rate in the traditional technique group was significantly greater than the BTS technique group $(15.00 \%$ vs. $0.00 \% ; \mathrm{P}=0.0266)$. The rectal perforation and the open conversion rate were $0.00 \%$ in both groups. There was no significant difference $(\mathrm{P}=1.0000)$ between the 2 groups in the false suture rate $(1.67 \%$ and $0.00 \%$, traditional and BTS, respectively). The apical capsule residue rates were $11.67 \%$ (traditional) and $6.67 \%$ (BTS) $(\mathrm{P}=0.2379)$. There was 1 patient with postoperative bleeding $(3.33 \%)$, which was due to the temporary bleeding from the trocar incision in the BTS technique group (vs. $0.00 \%)(\mathrm{P}=0.3333)$. A case of urinary leakage was found in the traditional technique group 
(1.67\%) (vs. $0.00 \%$ in BTS technique group, $\mathrm{P}=1.0000$ ). The re-operation and the surgical site infection rates were $0.00 \%$ in both groups. There was no significant difference in the postoperative stay, which was $5.85 \pm 1.16$ days in the traditional technique group and $5.70 \pm 1.88$ days in the BTS technique group. The remission times of urinary incontinence were $3.60 \pm 3.36$ months and $1.96 \pm 2.17$ months in the traditional and BTS groups, respectively $(\mathrm{P}=0.2586)$. The biochemical recurrence rates were $48.33 \%$ and $30.00 \%$, respectively $(\mathrm{P}=0.0465)$ (Table 4).

\section{Discussion}

The DVC is composed of veins that were the basis for the original name (dorsal venous complex). This concept was initially described by Santorini in 1724, and thus also became known as Santorini's plexus. With the advent of laparoscopic and robotic technology, understanding of the anatomy has increased; specifically, previously undescribed small arteries, which are probably either a terminal branch of the internal pudendal artery or a small branch of the prostatic capsular artery, have been differentiated from the plexus. Thus, the concept has been enlarged and is now referred to as the DVC, of which neither the acronym nor the eponym has been changed (9).

There was also a technological evolution in radical prostatectomy (RP), which could be divided into the following 2 terms: (I) evolution prompted by the miniinvasive technology; and (II) evolution brought about by enlargement of the DVC concept.

The original anatomic approach and DVC dissection method for open surgery was described by Walsh $(2,10)$, in which sharp dissection with a McDougal clamp is used to create a plane between the DVC and urethra. In 2009, Namiki et al. $(2,10)$ reported a blunt apical dissection of the DVC during anatomic radical retropubic prostatectomy. The puboprostatic ligaments were preserved and a groove was created by gentle blunt dissection with the right index finger between the urethra and DVC. A \#1 Vicryl tie was passed using Mixter forceps around the isolated DVC for ligation. Further ligations were performed for the most proximal extent of the isolated DVC. Mixter forceps were passed posterior to the DVC, which was transected with a 15-blade knife. The DVC was ligated upfront in a RP and subsequently transected before dissection of the prostate $(5,10)$, but in laparoscopic surgery the majority of procedures follow ligation of the DVC, resection of the prostate except the apex, transection with or without reconstruction of the bladder neck of the DVC, separation of the apex, and division of the urethra (4).

During the technological evolution accompanied by enlargement of the DVC concept, Porpiglia et al. described a selective suture of the DVC method in which the DVC was coagulated bilaterally by bipolar forceps and transected in the middle by cold scissors in an augmented pneumoperitoneal pressure of $16-18 \mathrm{mmHg}$ after antegrade dissection of the prostate (4). In the case of encountering small arteries, bipolar forceps were utilized again for coagulation, or pressuring by suction and subsequent selective suture was prepared for significant bleeding. In 2013, Hoshi et al. reported a DVC non-ligating and puboprostatic ligament-preserving technique in intrafascial nerve-sparing laparoscopic radical prostatectomy; the DVC was transected and sutured after the prostate had been antegrade-separated (11).

With the traditional technique for managing the DVC during non NVB-sparing eLRP surgery, the DVC is ligated after incision of the bilateral endopelvic fascia [a white line referred to as the arcus tendinous fascia pelvis (1)], but is not transected. It is not until the apex been separated, that the DVC division will be further processed. There are several defects regarding the traditional technique: (I) difficulty finding the DVC-urethral plane; (II) challenging technology for DVC dissection and suturing; (III) false suturing of the urethra or catheter; (IV) incomplete suturing of the DVC; (V) augmentation of bleeding (2) due to the difficulty of suturing; (VI) difficulty of suturing a widened DVC (3), which is due to pelvic adhesions or excessive fusion of the parietal and visceral components of endopelvic fascia (1); (VII) difficulty dissecting the prostate while the prostate to true pelvic volume ratio is high (3); (VIII) difficulty suturing the DVC and dissection of the prostate in cases of prominent pubic tubercles (3); (IX) loosening, displacement, or breakage of the sutures and further bleeding (3) with difficulty in separating the apex and apical residue.

By combining beforehand DVC transection with nonDVC ligation, we have described a novel technique for non NVB-sparing eLRP in which the DVC was transected and sutured before antegrade separation of the prostate in a pneumoperitoneal pressure of $18 \mathrm{mmHg}$. The stitching followed the transection, or when encountering small arteries, alternation of dividing and suturing was recommended. By comparing research, the BTS technique was shown to reduce the $S T, \mathrm{BL}_{c}, \mathrm{BL}_{\mathrm{e}}$, and transfusion rate. There was no significant difference in peri-operative complications compared to the traditional technique. The 


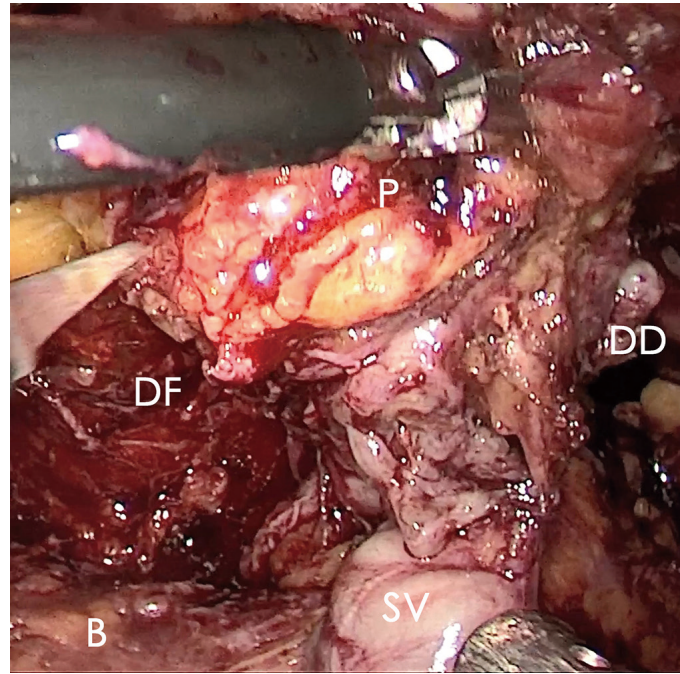

Figure 6 The prostate could be dragged or rotated due to the extended portion of the urethra released by dissection of the apex. $\mathrm{P}$, prostate; DF, Denonvilliers' fascia; DD, deferent duct; B, bladder; $\mathrm{SV}$, seminal vesicle.

efficiency and safety of the BTS technique were superior to the traditional technique.

The concept of beforehand treatment of DVC has also appeared in non NVB-sparing eLRP (11), but similar to open surgery, the retrograde blood flow above the prostate was strictly controlled (Hem-o-Lok ${ }^{\mathrm{TM}}$ in LRP). It seems that the uncontrolled prostate pedicles were considered to be related to the retrograde blood flow and to the probable bleeding. That was perhaps why the DVC was not completely treated in most LRPs or robot-assistant LRPs. Based on our results, although the DVC was transected using an ultrasound knife, the uncontrolled pedicles did not significantly increase the blood loss. It was safe to transect the DVC directly and stitch the distal stump before division of the bilateral prostatic pedicles.

According to the researcher's experience, the time saved with respect to precise suture hemostasis with no loosening or displacement of thread suggests the following: (I) wide DVC can be treated at leisure; (II) false suture of the anterior wall of the urethra and catheter was avoided; (III) the prostate could be dragged or rotated due to the extended portion of the urethra (10-40\% of the functional urethra) released by dissection of the apex compared with the membranous urethral length revealed in MRI (12), that benefited patients with a high prostate to true pelvic volume ratio (Figure 6). All of these mixed factors could not be ignored.
In the process of BTS of DVC, several points should be paid more attention: (I) the pneumoperitoneal pressure increased to $18 \mathrm{mmHg}$ to reduce the bleeding from DVC; (II) no suction or aerofluxus via the trocar; (III) the distal DVC stump stitched in a proximal-distal-proximal fashion to avoid the Hem-o-Lok related bladder erosion; (IV) a small-sized Hem-o-Lok ${ }^{\mathrm{TM}}$ utilized to consolidate the suture, in avoiding of the loosening of the suture.

As quantity of the cases with BTS technique was small, as the advantages of BTS technique in the cases with big prostate or high prostate to true pelvic volume ratio were not statistically confirmed, a further enlarged prospective research is needed.

\section{Conclusions}

The BTS technique was shown to be more effective and safer than the traditional technique for managing the DVC and dissection of the prostate in non NVB-sparing eLRP, using this new technique, the procedure of eLRP could be further optimized.

\section{Acknowledgments}

We would like to thank International Science Editing (http://www.internationalscienceediting.com) for languageediting this manuscript.

Funding: This research was supported by the Agricultural and Social Research Projects of Jiading District, Shanghai (JDKW-2018-W09) and the Youth Talents Plan of Shanghai Ruijin Hospital North (2019RCPY-B12). The funders had no role in this research.

\section{Footnote}

Reporting Checklist: The authors have completed the STROBE reporting checklist. Available at http://dx.doi. org/10.21037/gs-20-813

Data Sharing Statement: Available at http://dx.doi. org/10.21037/gs-20-813

Conflicts of Interest: All authors have completed the ICMJE uniform disclosure form (available at http://dx.doi. org/10.21037/gs-20-813). The authors have no conflicts of interest to declare.

Ethical Statement: The authors are accountable for all 
aspects of the work in ensuring that questions related to the accuracy or integrity of any part of the work are appropriately investigated and resolved. All procedures performed in this study involving human participants were in accordance with the Declaration of Helsinki (as revised in 2013). The study was approved by institutional ethics committee of Shanghai Ruijin Hospital and informed consent was taken from all the patients.

Open Access Statement: This is an Open Access article distributed in accordance with the Creative Commons Attribution-NonCommercial-NoDerivs 4.0 International License (CC BY-NC-ND 4.0), which permits the noncommercial replication and distribution of the article with the strict proviso that no changes or edits are made and the original work is properly cited (including links to both the formal publication through the relevant DOI and the license). See: https://creativecommons.org/licenses/by-nc-nd/4.0/.

\section{References}

1. Tavukçu HH, Aytac O, Atug F. Nerve-sparing techniques and results in robot-assisted radical prostatectomy. Investig Clin Urol 2016;57:S172-84.

2. Cristini C, Di Pierro GB, Leonardo C, et al. Safe digital isolation of the santorini plexus during radical retropubic prostatectomy. BMC Urol 2013;13:13.

3. Sasaki H, Miki J, Kimura T, et al. Upfront transection and subsequent ligation of the dorsal vein complex during laparoscopic radical prostatectomy. Int J Urol 2010;17:960-1.

4. Porpiglia F, Fiori C, Grande S, et al. Selective versus standard ligature of the deep venous complex during

Cite this article as: Pan JW, Jin XW, Luo FX, Jin W, Tu WC, Zhang X, Wang XJ, Huang BX, Xu D, Lu GL, Zhao Y, Shao Y. Beforehand transection and suturing (BTS) of the dorsal vascular complex: a novel technique in laparoscopic radical prostatectomy. Gland Surg 2020;9(6):2116-2124. doi: 10.21037 /gs-20-813 laparoscopic radical prostatectomy: effects on continence, blood loss, and margin status. Eur Urol 2009;55:1377-83.

5. Tobias-Machado M, Pazeto CL, Neves-Neto OC, et al. A Safe teaching protocol of LRP (laparoscopic radical prostatectomy). Int Braz J Urol 2018;44:273-9.

6. Milonas D, Venclovas $\check{Z}$, Gudinaviciene I, et al. Impact of the 2014 International Society of Urological Pathology Grading System on Concept of High-Risk Prostate Cancer: Comparison of Long-Term Oncological Outcomes in Patients Undergoing Radical Prostatectomy. Front Oncol 2019;9:1272.

7. Paterson NR, Lavallée LT, Nguyen LN, et al. Prostate volume estimations using magnetic resonance imaging and transrectal ultrasound compared to radical prostatectomy specimens. Can Urol Assoc J 2016;10:264-8.

8. Gross JB. Estimating allowable blood loss: corrected for dilution. Anesthesiology 1983;58:277-80.

9. Power NE, Silberstein JL, Kulkarni GS, et al. The dorsal venous complex (DVC): dorsal venous or dorsal vasculature complex? Santorini's plexus revisited. BJU Int 2011;108:930-2.

10. Namiki K, Kasraeian A, Yacoub S, et al. Blunt apical dissection during anatomic radical retropubic prostatectomy. BMC Res Notes 2009;2:20.

11. Hoshi A, Usui Y, Shimizu Y, et al. Dorsal vein complex preserving technique for intrafascial nervesparing laparoscopic radical prostatectomy. Int J Urol 2013;20:493-500.

12. Kania P, Wośkowiak P, Salagierski M. Preservation of continence in radical prostatectomy patients: a laparoscopic surgeon's perspective. Cent European J Urol 2019;72:32-8 